\title{
Adapting and usability testing of an eLearning resource to enhance healthcare professional provision of sexual support across cancer care
}

\author{
Sharon Linsey Bingham ${ }^{1,2}\left[\right.$ (]) Cherith Jane Semple ${ }^{1}\left[\right.$ Carrie Flannagan $^{1}\left[\right.$ Lynn Dunwoody $^{3}[$
}

Received: 16 September 2021 / Accepted: 31 December 2021 / Published online: 12 January 2022

(c) The Author(s), under exclusive licence to Springer-Verlag GmbH Germany, part of Springer Nature 2022

\begin{abstract}
Objectives To adapt the theory-driven and positively evaluated Maximising Sexual Wellbeingl Prostate Cancer (MSWIPC) eLearning resource to an eLearning resource suitable for health professionals (HPs) working with mixed cancer populations, followed by usability and acceptability testing.

Methods Guided by Person-Based Approach (PBA) and Biopsychosocial Model, the MSWIPC was adapted by combining evidence from the literature, an expert group ( $n=27$ : patients, partners, and HPs working in cancer care) and the research team. New content was developed relevant for a mixed cancer population. The Maximising Sexual Wellbeingl Cancer Care (MSWICC) eLearning prototype was usability tested and modified with HPs using "think aloud" interviews $(n=18)$.

Results Many identified sexual challenges were common across cancer populations, with additional information required for breast, colorectal, gynaecological, head and neck, and prostate cancers. During the testing phase, navigational difficulties were identified and resolved. HPs reported the MSWICC as engaging, informative, and relevant with helpful communication and signposting tools to support practice.

Conclusion This systematic and iterative PBA yielded important insights to enhance the content and usability of MSWICC. This novel resource provides HPs working across cancer care with tools to potentially address the gap in knowledge and skills and positively impact future sexual healthcare provision across cancer care.
\end{abstract}

Keywords Cancer $\cdot$ e-Learning $\cdot$ Person-based approach $\cdot$ Sexual health $\cdot$ Qualitative research $\cdot$ Intervention adaptation

Sharon Linsey Bingham

sharon.bingham@ northerntrust.hscni.net

Cherith Jane Semple

cherith.semple@setrust.hscni.net

Carrie Flannagan

c.flannagan@ulster.ac.uk

Lynn Dunwoody

1.dunwoody@ulster.ac.uk

1 School of Nursing, Ulster University, Shore Road, Jordanstown, Northern Ireland

2 Northern Health \& Social Care Trust, Antrim, Northern Ireland

3 School of Psychology, Ulster University, Cromore Road, Coleraine, Northern Ireland

\section{Background}

One in two people are estimated to receive a diagnosis of cancer in their life [1]. Treatments offered can cause distressing and enduring side effects on sexuality, both for the patient and their partner [2-4]. Clinical guidelines highlight the importance of healthcare professionals (HPs) providing routine sexual support to patients and their partners across the treatment trajectory, which addresses the biological, psychological, and social challenges, potential or presenting [5-7]. Yet, research suggests that despite many HPs identifying that sexual support is part of their role, provision is inconsistent and often absent [8,9]. Patients frequently report that they do not receive information about potential sexual challenges or strategies to help them navigate sexual challenges [8]. A key barrier to the provision of HP-led sexual support is a lack of knowledge of the sexual challenges faced by patients and strategies to promote support [10, 11]. Furthermore, the provision of HP-led sexual support 
is influenced by HP's fears of patient embarrassment, not knowing how to frame sexual support conversations and external influences including lack of resources, referral pathways, time, and privacy $[10,11]$.

To enable provision of routine sexual support by HPs, there is a need to increase HP knowledge, provide communication tools, supportive resources, and referral pathways [10, 11]. Studies demonstrate that education can have a positive impact on levels of knowledge, sexual attitudes, and beliefs, translating to improved self-efficacy for HPs and enhanced provision of sexual support. However, educational interventions are often limited to a specific tumour group such as breast or prostate or gender [12-15], with many adopting face-to-face delivery $[12,13,15]$.

Members of the research team previously developed, tested, and positively evaluated an evidence and theorybased eLearning resource (Maximising Sexual Wellbeingl Prostate Cancer (MSWIPC)) to support HPs provide sexual care to men with prostate cancer and their partners. Details of MSWIPC intervention development, content and evaluation have been previously published $[12,16]$. This resource addressed the key attitudinal barriers identified by the literature, to the provision of sexual support for men with prostate cancer and their partners. There is a lack of rigorously developed and efficacious eLearning interventions that are scalable for use by HPs working across mixed cancer populations. The aim of this study was to adapt the MSWIPC to the Maximising Sexual Wellbeingl Cancer Care (MSWICC) eLearning resource, for use by HPs across cancer care and test its acceptability for use in routine cancer care settings. The objectives are to (1) provide a detailed insight into key design decisions when adapting the MSWIPC to the MSWICC based on extensive user testing, the use of the theoretical and evidence base and (2) explore HPs views on the MSWICC to promote sexual well-being in routine cancer care.

\section{Methods}

\section{Adaptation process}

The original MSWIPC [12] and its brief communication framework [16], Engagement, Assessment, Support, and Signposting (EASSi) were developed using the Theoretical Domains Framework [17] and underpinned by the Theory of Planned Behaviour [18] and Social Cognitive Theory [19], which were retained for the MSWICC.

To adapt the MSWIPC, the person-based approach (PBA) [20] provided a systematic and robust method to combine user-centred design methods with evidence-based behaviour change methods. An extensive literature review indicated that HPs across cancer care encounter similar barriers to providing sexual support such as a lack of knowledge, clinical time, and confidence in right language to use [10, 11, 16]. Furthermore, patients faced similar sexual challenges across tumour groups for example, dealing with loss of sexual desire, function, or pleasure, body image challenges, and effects on emotions [2-4]. Given the similar sexual challenges experienced, a "Core" advice section was collated addressing common physical and psychosocial concerns. Further optional sections for tumour specific concerns for breast, colorectal, gynaecological, head and neck, and prostate cancer were provided, e.g. changes to or loss of a breast, and problems with mouth or kissing. Advice was generated from sources including empirical studies, international guidelines, and evidenced based eLearning resources. Furthermore, the MSWICC required additional content to address sexual challenges faced by women, broader referral options, and supporting resources.

The Biopsychosocial Model [21] was used as a scaffold for the development of all new content to ensure sexual challenges were holistically addressed. Collaboratively, HPs (end users) and the research team initially developed the new content, to promote acceptability and effectiveness of the MSWICC [20]. An expert stakeholder group (ESG) comprised 27 members (nine patients with cancer, one partner, eleven nurse specialists, three allied health professionals, two oncologists, and one services manager) provided iterative feedback on draft content. Changes (see Table 1 for a summary of expert group suggested changes) were adopted if they were in keeping with the guiding principles (Supplement 1), leading to development of MSWICC prototype, ready for optimisation testing [20]. Figure 1 outlines the adaptation and optimisation process over 6 prototype versions.

\section{Study design (for optimisation of MSW|CC)}

To optimise the MSWICC and in keeping with PBA intervention development framework, qualitative testing was undertaken, which iteratively elicited and incorporated HPs' perspectives and preferences into the intervention. One-toone think-aloud interviews [22] were conducted (by SLB), either in-person or remotely and reported in accordance with the update FRAME guidance [23] for reporting on intervention adaptation along with further recommendations from ADAPT guidance v1.0 [24]. Think-aloud interviews captured participants' verbalised thoughts, as they systematically worked through the MSWICC content (Supplement 2), highlighting HPs views on the acceptability and usability of the intervention.

\section{Participants}

Participants were purposively recruited across cancer care professional roles, tumour groups and represented five 
Table 1 Summary of expert group changes to MSWICC content

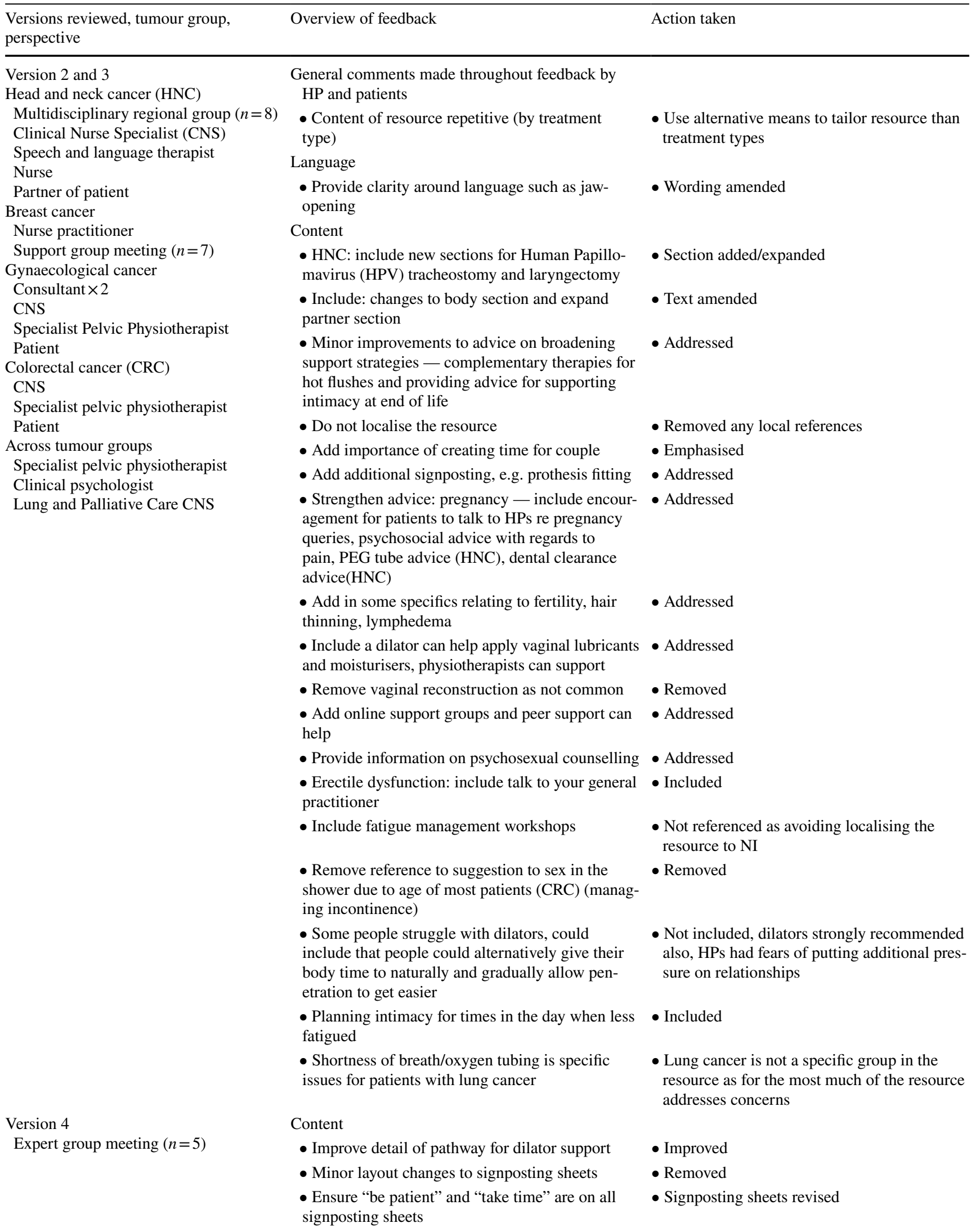




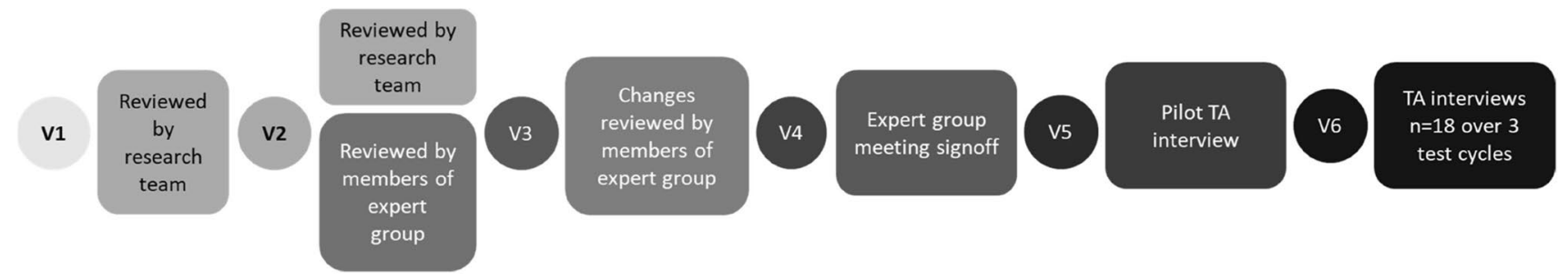

Fig. 1 Adaptation and optimisation process for MSWICC. $V$, denotes prototype version

Health and Social Care Trusts (HSCTs), acute and community settings in Northern Ireland. Eligible participants were registered HPs, working directly with patients with cancer who could provide informed consent. Based on similar work in the field, the sample size was estimated as $n=20$.

\section{Procedure}

The study was approved by the Research Ethics Committee for Northern Ireland (IRAS project number 259926). Participants were recruited through local collaborators within HSCTs and written informed consent provided. Each participant reviewed at least two steps of the MSWICC, tailored to their area of clinical expertise. To facilitate testing, HPs used either a Microsoft ${ }^{\circledR}$ PowerPoint ${ }^{\circledR}$ mock-up version of the $\mathrm{MSWICC}$ or an online version (dependent on testing cycle). All 60-min interviews were audio or video recorded and transcribed, by the first author, who also took additional notes on key issues to inform modifications during and immediately after each interview. Occasional prompts were used to clarify or direct participants to content overlooked [22]. Data were collected from February 2020 to October 2020.

\section{Data analysis}

Data analysis commenced upon completion of the first thinkaloud interview and continued iteratively until all interviews were completed. Data that specifically related to potential barriers to engagement with the MSWICC were deductively analysed and presented in table format [25], under pre-determined codes: appearance, content, navigation, and functionality. For each potential barrier recorded, the research team considered potential modifications to address the barrier. Criteria set out by Bradbury et al. [25] supported modification decision-making. Transcribed data pertaining to HPs views on the MSWICC was inductively thematically analysed, as outlined by Braun and Clarke [26]. Codes were reviewed by two other members of the research team (CJS and CF), organised into themes, with disagreements resolved through discussion. Thematic saturation was achieved (no new themes regarding MSWICC usability and acceptability identified) after 18 one-to-one think-aloud interviews over 3 test cycles.

\section{Results}

Demographic information of HP participants is provided in Table 2 . The findings from think-aloud interviews provided data which (1) informed modifications to the MSWICC and (2) explored HP views of the MSWICC.

(1) Informing modifications

Feedback relating to modifications and actions implemented across the three test-cycles centred around four main areas: appearance, content, navigation, and functionality; these have been presented in detail within Table 3. Important navigational issues were identified in test cycle two. The navigation issues were resolved and confirmed by test cycle three.

(2) HPs' views of the MSWICC

Thematic analysis on HPs' views of the MSWICC identified two main themes: (1) Sexual support: It is the HP's role but there is room for improvement and (2) the MSWICC: meeting HPs' needs.

\section{Theme 1: Sexual support: It is the HP's role but there is room for improvement}

Participants identified that sexual support is the HP's role, but this is seldom integrated as part of standard practice. This is highlighted through two subthemes: sexual support in cancer care is often side-lined by HP's and mediating factors to the provision of sexual support in cancer care.

\section{Subtheme 1.1: Sexual care in cancer care is often side-lined by HP's}

More often participants reported sexual support in cancer care was side-lined, with participant 16 (P16) reflecting this was "maybe due to people being embarrassed including myself as a HP and the patient." Sexual support was usually limited to the treatment consent process; therefore, patients seem to be afforded little support to navigate sexual challenges later in the treatment trajectory, as illustrated below. 
Table 2 Participant demographic information

\begin{tabular}{llll}
\hline Healthcare professionals & & \\
\hline Test cycle & Participant ID & Gender & Job title \\
\hline 1 & P1 & Female & Clinical nurse specialist (CNS) (colorectal) \\
1 & P2 & Female & CNS (gynaecological) \\
1 & P3 & Female & Radiotherapist \\
1 & P4 & Female & Oncology physiotherapist \\
2 & P5 & Female & CNS (head and neck) \\
2 & P6 & Female & CNS (gynaecological) \\
2 & P7 & Female & Breast care nurse \\
2 & P8 & Female & Chemotherapy nurse \\
2 & P9 & Female & Practice education nurse \\
2 & P10 & Male & Consultant surgeon (gynaecological) \\
2 & P11 & Female & Oncology physiotherapist \\
2 & P12 & Female & CNS (head and neck) \\
3 & P13 & Female & Oncology physiotherapist \\
3 & P14 & Male & Nurse practitioner (head and neck) \\
3 & P15 & Female & Chemotherapy nurse \\
3 & P16 & Female & CNS (colorectal) \\
3 & P17 & Female & Chemotherapy nurse \\
3 & P18 & Female & CNS (head and neck) \\
\hline
\end{tabular}

"I do it [provide sexual support] pre surgery and probably do not revisit unless raised as an issue in the health needs assessment form...." (P16)

This practice was considered reflective of a wider culture of limited provision of HP-led sexual support in cancer care and echoed by P9 sharing "we are not doing this," which for some HPs raised concerns that the needs of some patients were not being met.

"Patients are probably wondering if people are going to ever talk to them about not having an erection again.

It really does get side-lined." (P14)

Sexual care was considered by HPs to be both important and integral to the provision of person-centred cancer care. This was challenging, with HPs having trouble initiating sexual support conversations or offering support, amplified in the presence of a partner or family member with HPs perceiving that "patients don't want to speak out of turn about private relationships.” (P8)

\section{Subtheme 1.2: Mediating factors to the provision of sexual support in cancer care}

Cognisant that providing sexual support was the HPs role, participants also identified three main influences to providing sexual support; these were HP-related factors, patient characteristics, and organisational setting. In considering HP-related factors, most participants reported they felt ill-equipped to address sexual problems, reflecting that they, alongside their oncology colleagues, lacked both knowledge and access to training.

"As HP we don't have support for this, sometimes we get asked questions, but we need help." (P17)

HPs specifically wanted skilled on how to approach sexuality sensitively, especially with older patients, to know the right language to use, and to be equipped with strategies to help patients cope and achieve sexual pleasure. There was also a desire for knowledge of referral pathways for additional support. Many participants identified that skill development was necessary to increase self-efficacy and reduce feelings of awkwardness or embarrassment during patient-professional consultations.

"Apart from the basic ways to do that [talk about sexual problems] I wouldn't know much more than that... so there is definitely a learning need there about what else is available and how else that can be achieved." (P16)

"I don't have the right words to start a conversation, ... any tool that can help us talk about normal bodily functions more openly and honestly is a good thing...." (P10)

Most participants agreed that providing sexual support was part of their role as an HP, yet some acknowledged that other members of the multidisciplinary team were better placed, for example the clinical nurse specialist or pelvic physiotherapist. Some reported they previously 
Table 3 Utilisation of data generated from TA interviews

\begin{tabular}{|c|c|c|c|}
\hline & Cycle 1 (MS PowerPoint) & Cycle 2 (Online version) & $\begin{array}{l}\text { Cycle } 3 \text { (Online resource and MS Pow- } \\
\text { erPoint) }\end{array}$ \\
\hline Appearance & $\begin{array}{l}\text { Improve readability: split larger para- } \\
\text { graphs (step 1) }\end{array}$ & $\begin{array}{l}\text { Increase text size (to enhance presenta- } \\
\text { tion of step } 2 \text { specific tumour section } \\
\text { response slides) } \\
\text { Ensure font consistency }\end{array}$ & \\
\hline Content & $\begin{array}{l}\text { Extend examples of good practice (single } \\
\text { and LGBT as is provided in 'end of } \\
\text { life' section) } \\
\text { Remove repetitive slide (Step } 2 \text { describ- } \\
\text { ing EASSi Framework) } \\
\text { Language } \\
\text { (1) Increase acceptability (should to may, } \\
\text { should to could) } \\
\text { (2) Reflect clinical practice, e.g. remove } \\
\text { specific advice relating to treatment } \\
\text { and pregnancy, ask patients to avoid } \\
\text { pregnancy and speak to HP if there are } \\
\text { any concerns } \\
\text { (3) Remove specific mention on hormo- } \\
\text { nal or non-hormonal vaginal moisturis- } \\
\text { ers, rather suggest 'designated vaginal } \\
\text { moisturisers.' } \\
\text { Improve relevance of video content } \\
\text { (include emotional concerns, body } \\
\text { image and coping with menopausal } \\
\text { symptoms) }\end{array}$ & $\begin{array}{l}\text { Include product disclaimer (Liz video } \\
\text { Part 1) } \\
\text { Amend online support options - UK } \\
\text { wide relevance and immediate rel- } \\
\text { evance content } \\
\text { Improve title clarity in step 2: support } \\
\text { Remove repetitive slide (step } 2 \text { support } \\
\text { prior to psychosocial effects) } \\
\text { Broaden Gynaecological signposting } \\
\text { to increase relevance across types of } \\
\text { tumours } \\
\text { Minor changes (Improve advice clarity.) }\end{array}$ & $\begin{array}{l}\text { Change wording relating to 'main role of } \\
\text { partner' to enhance relevance } \\
\text { Increase clarity for HPs in step } 2 \text { support: } \\
\text { dilator support (gynaecological), timing } \\
\text { of intimacy (stoma activity (colorectal)) } \\
\text { and use of heat moisture exchange filters } \\
\text { (head and neck) } \\
\text { Reorganise ordering of } 2 \text { questions in } \\
\text { couple communication activity (sign- } \\
\text { posting sheets) to encourage progression } \\
\text { in thinking }\end{array}$ \\
\hline Navigation & $\begin{array}{l}\text { Remove unnecessary signposting from } \\
\text { advice pages in step } 2\end{array}$ & $\begin{array}{l}\text { Enhance navigation (poor use of side- } \\
\text { way navigation) } \\
\text { Improve signposting to avoid missed } \\
\text { layered sections (step 2.) } \\
\text { Reword 'Back to Start' to 'Back to previ- } \\
\text { ous section' (step 2.) }\end{array}$ & $\begin{array}{l}\text { Colour tabs in layer sections (step 2) to } \\
\text { enhance navigation }\end{array}$ \\
\hline Functionality & & $\begin{array}{l}\text { Add functionality to step } 1 \text { response } \\
\text { activity (no response confusing.) } \\
\text { De-bug step } 2 \text { support advice boxes } \\
\text { (information disappears off page) } \\
\text { Ensure icons/text do not overlap (step } 1 \\
\text { response screens.) } \\
\text { Compress videos for low bandwidth }\end{array}$ & \\
\hline
\end{tabular}

referred patients to voluntary/community sector cancer care providers for sexual support to avoid their own discomfort in undertaking such discussions.

"It's not an easy thing for HPs to talk to patients about sexuality so you can signpost to Macmillan for more information." (P13)

Patient characteristics such as sexual orientation, older age, and an age gap between HP and patient (where the HP was younger) were highlighted as influencing HPs' decision-making on the provision of sexual support. It was noted that HPs provision of sexual support to same-sex couples was not routine practice, "only something that is talked about if we are forced to," (P14) with a belief that this may be reflective of the more culturally conservative locale within NI. When patients were of an older age, often HPs considered sexuality to be less relevant or did not wish to be perceived as inappropriate; with P2 sharing concerns relating to whether the "husband has dementia or is dead..." yet also aware that there is a risk that older patients want support exemplified by reporting, "maybe I'm wrong...I'm assuming...maybe they do." Furthermore, HPs reported patient embarrassment could be reduced if the HP and patient were the same gender, although this could be indicative of HP preference to reduce personal embarrassment.

Organisational challenges to providing sexual support related to lack of time, privacy, and the change to virtual appointments due to COVID-19 restrictions. Participants had contrasting views on time, with P14 reporting, "I only 
have 20-30 min to cover a lot of topics." Contrary to this view, some described lack of time as an excuse to avoid addressing an uncomfortable topic, with others reporting there was time,

"I'm sure people will say this [they don't have time] but I do have time. I work with 5 consultants and oncology team and on occasions I'm pressed but usually I have time." (P16)

HPs provided examples of how to integrate these conversations during clinical care, to include physiotherapy massage, administration of intravenous chemotherapy, or holistic needs assessment consultations. HPs performing these roles may have greater autonomy to provide sexual care, which may not be indicative of all HPs within cancer care. The lack of privacy afforded by a curtained cubical was not conducive to having sexual support conversations. Furthermore, the transition to virtual appointments, due to COVID-19 restrictions, saw a decrease in sexual support conversations, an interesting finding given the potential privacy afforded, with P16 reporting,

"The problem at the minute now is that it because of COVID it is a virtual appointment and people are more reluctant to have these conversations... I encourage people to bring their partner with them or someone who they trust implicitly, virtually although this is not happening...partners are not on the speaker phone...." (P16)

\section{Theme 2: MSW|CC: Meeting HPs' needs}

Participants suggested that the MSWICC had the potential to address many of the barriers identified by HPs to enhance future provision of sexual support in cancer care. Findings to support this position were evidenced in the following three subthemes: the MSWICC (1) has engaging features, (2) it equips and empowers HPs, and (3) is an acceptable and relevant resource.

\section{Subtheme 2:1: Engaging features}

The MSWICC was viewed as easy to read and was endorsed as having credible content which addressed relevant sexual challenges faced by patients. Multimedia interactive elements appealed to participants and were "immediately engaging" (P9) and supported reflective practice. Patient video content was well received, with the patient voice being regarded as "the best learning tool we have" (P18). Graphics used throughout the resource were viewed positively and reported as "memorable" and "contemplative" (P9). Navigation through the MSWICC was seen as "intuitive" (P14). The key messages built throughout the three steps of the
MSWICC, which enabled users to progressively be informed without being overwhelming. HPs identified the MSWICC as one which they would spend time with, rather than using to mark off as a task completed.

\section{Subtheme 2.2: Equips and empowers}

The content within the MSWICC was perceived as informative; it increased HPs' knowledge of sexual challenges faced, patients' and partners' needs and desire for support across treatment trajectory, relevant advice, resources, and referral pathways. Frequently, participants reported learning new information on the psychosexual challenges, navigating new relationships, and for disease-specific sexual challenges such as managing a percutaneous endoscopic gastrostomy (PEG) tube or a colostomy/ileostomy. Furthermore, participants felt that the MSWICC aided understanding and normalised sexual challenges and equipped HPs to provide sexual support with participant 12 reporting "I could anticipate and pull out as items in my toolkit [referring to the MSWICC] to help me navigate conversations."

The EASSi communication framework embedded within the resource was regarded as a reassuring guide to direct HPs' communication. Participants acknowledged that EASSi provided them with advice for patients that was succinct, yet "practical" (P9) and "very reassuring... because it is giving you a step-by-step guide." (P10), HPs also welcomed the printable one-page EASSi framework for future reference. This communication framework was regarded as suitable for further adaption to help early career HPs communicate about other challenging healthcare issues.

Signposting within the resource, which included the hyperlinks to webpages, referral pathways, and printable signposting sheets, was deemed helpful, particularly to facilitate communication with patients who were "too embarrassed to talk" (P17). The inclusion of the "couple's communication activity" within the signposting sheet was felt by some to be "quite challenging [for patients]," (P10) as patients and partners might find it difficult to discuss sexual behaviour with each other, although overall its benefits were thought to outweigh these concerns.

Strategies promoting self-efficacy, such as role-play with a colleague and goal setting were well received, complementing the communication framework, to improve confidence. HPs reported a sense of empowerment, with a readiness to put knowledge into action with one participant reporting "...see reading through that ...I would go for it now." (P17)

\section{Subtheme 2.3: Acceptable and relevant resource}

The MSWICC content was considered acceptable to participants. It was perceived as "all encompassing" and "true 
to life" (P17) reflecting common patient reported clinical issues, for example, changing levels of sexual desire and changed in roles in the household "my wife has become my carer" (P18). Core messages were described as "positive" yet "realistic." (P8)

Mostly participants highlighted that advice was aligned with current best practice, promoting strategies used by experts in the field; however, two issues were identified by some participants. Firstly, promotion of a retailed product, to customise the depth of penetration to reduce pain during sex was unknown to HPs, but on reflection HPs were interested to review the product as a potential device that could be recommended in future to patients; the second concerned HPs' sensitivity when recommending the use of dilators to aid intercourse for patients with cervical cancer.

"This is what they are told to do after treatment and that has that whole stigma with them [patients] and they hate using them [dilators]." (P6)

\section{Discussion}

Findings from our study have indicated that akin to many other HPs globally, the provision of HP-led sexual support is hindered by similar barriers such as lack of knowledge, time and resources, difficulties communicating around sexual concerns, and biases towards patient characteristics, such as single, elderly, and LGBTS end of life trajectory [10, 11]. This study highlighted the need for HPs to improve the provision of sexual support in routine cancer care. Furthermore, this novel theory-driven and evidence-based MSWICC eLearning resource (https://talkingaboutsex-cancercare. org) has addressed key barriers to the provision of sexual support through the production of an accessible resource for HPs which includes the EASSi framework to help HPs structure sexual wellbeing conversations as part of routine cancer care [10,11]. The MSWICC was deemed acceptable, usable, and engaging and could support the implementation of global healthcare guidelines' recommendations [5-7]. The MSWICC included adapted and new content, delivered through a range of multimedia methods, which enhanced attractiveness and engagement. This included text, patient and HP videos, signposting sheets for general use, and specific tumour groups and referral pathways. The planning and development of digital interventions using extensive usertesting, such as MSW ICC, is often not reported in detail. Consequently, little insight into key design decisions is provided, and how or why an intervention might work for whom, or indeed the fundamentals of how the intervention was informed by both theory and the evidence-base [26]. This study has addressed this gap by methodically detailing the systematic and iterative application of the PBA which optimised the MSWICC. The authors believe this paper has documented the adaptation of the first eLearning resource to enhance the provision of sexual support across cancer care.

Patient and public involvement (PPI) is a feature of best practice when developing healthcare resources and is completed alongside the systematic application of the theory and evidence base [27]. Co-production, a PPI approach, within research emphasises the importance of power-sharing to promote inclusive research practices, valuing and respecting knowledge from different sources [28]. For this study, substantial effort was directed to bring experts with experience (patient, partner, and HPs) into the research process through the iterative involvement of the ESG $(n=27)$. The range of viewpoints provided insightful perspectives on the evidence base, which reiterated and importantly led to developing new content within a biopsychosocial context. ESG also advised on tone, language, and supporting resources. Establishment of a representative ESG was a challenge to ensure views, perspectives, and experiences of each were accounted for, especially given the variable time, skills, and interest of members [27]. Following recommendations [29] and recognition of the diversity of the group, the researcher worked to build trust and ensured that both professional and non-professional perspectives were equally valued. Participation was maximised through a flexible approach to communication, therefore HPs met both as a group and individually to delve into specific aspects of the content, and patient/ partners met on a small group basis or communicated via email or in writing. Such considerations served to strengthen the relevance and quality of the MSWICC prior to qualitative testing, potentially reducing optimisation test cycles [29].

The TA interviews permitted the capture of real-time observable and audible reactions of HPs [22] and complemented the input of the ESG, by providing an in-depth understanding of the perspective of end-users [30]. Important navigational problems identified would not have been apparent using retrospective interviews, as participants were unknowingly missing key information. Prompts were used to direct participants attention to the missed sections, which identified the need for enhanced navigation to ensure missed content was accessed. Previous authors raised concerns regarding validity of TA findings when participant thoughts are interrupted by prompts [31]; however, this paper argues prompts were essential to understanding fundamental navigational problems prior to more costly implementation.

The PBA's qualitative optimisation method has been critiqued as labour intensive [30], yet it is a necessary process to ensure that interventions address their design objectives and avoid the risk of little or no effect at all [32]. Although the use of TA interviews afforded a time investment, this study promoted efficiency through adherence to a research guidance framework [33] which ensured clear designation of research responsibilities and established communication 
pathways between the researcher and local collaborators and agreed key roles at the outset of each study phase.

The MSWICC via an online platform provides flexible access for HPs to engage with learning content on patient sexual issues, which overcomes clinic scheduling and geographic barriers to supporting continuing professional development [34]. Existing interventions targeting the provision of sexual support in cancer care have limitations in reach due to adopting a face-to-face approach [14, 15, 35, 36]. Ensuring quality, key principles for asynchronous eLearning interventions [37] were addressed, with end users advising on content detail and tone, design, and intuitive navigation outside of the provision of technical support. The testing process utilised multiple devices which revealed appearance and functionality issues which could be addressed to prevent cross-device incompatibility issues during implementation [38].

\section{Conclusion}

The MSWICC is an acceptable and usable intervention addressing the current barriers affecting provision of sexual support in cancer care. A transparent and detailed guide into the iterative development of an eLearning resource has highlighted the benefits of co-production inherent within PBA, strategies to minimise optimisation effort and support decision-making, and key principles used to maximise engagement. This could guide development of future sexual support interventions required across other chronic conditions [39].

\section{Study limitations}

The study sample was purposively selected, although broader representation of tumour groups, ethnicity, geographical location, and gender may have provided greater insight into nuances in the provision of sexual support, which could enhance the relevance of the intervention to specific groups. It could be argued that study participants had a strong clinical interest in sexual care, which may have positively biased the feedback during the TA interviews; however, this expertise and commitment was integral to the success of the study. Finally, although unlikely given the positive and negative comments received, the presence of the researcher may have positively biased elements of the critique.

\section{Clinical implications}

The MSWICC is an acceptable and usable intervention to enhance the provision on sexual support in cancer care, but it is unknown if it will successfully reduce barriers affecting the provision of sexual support in cancer care. The next step is to conduct a single-arm evaluation of the MSWICC investigating its impact on sexual attitudes and beliefs of HPs relating to the provision of sexual support in cancer care.

Supplementary Information The online version contains supplementary material available at https://doi.org/10.1007/s00520-022-06798-w.

Acknowledgements The authors jointly wish to acknowledge the leadership and expertise of Prof. Eilís McCaughan throughout this study.

Author contribution Optional.

Funding We would like to acknowledge funding from Movember/ TrueNth/Prostate Cancer UK and the Department for the Economy, Northern Ireland.

Data availability The data that support the findings of this study are available from the corresponding author upon reasonable request.

Code availability N/A.

\section{Declarations}

Ethics approval The study was approved by the Research Ethics Committee for Northern Ireland (IRAS project number 259926).

Consent to participate Informed consent was obtained from all individual participants included in the study.

Consent to publication Participants consented to the publication of research.

Conflict of interest The authors declare no competing interests.

\section{References}

1. Ahmad AS, Ormiston-Smith N, Sasieni PD (2015) Trends in the lifetime risk of developing cancer in Great Britain: comparison of risk for those born from 1930 to 1960 . Br J Cancer 112(5):943-947

2. Bober SL, Kingsberg SA, Faubion SS (2019) Sexual function after cancer: paying the price of survivorship. Climacteric 22:558-564

3. Di Mattei VE, Perego G, Taranto P, Mazzetti M, Marotta E, Candiani M, Salvatore S (2020) The long-term effects of cancer treatment on sexuality and couple relationships. Fam Process. https:// doi.org/10.1111/famp.12604

4. Charif AB, Bouhnik AD, Courbière B, Rey D, Préau M, Bendiane MK, Peretti-Watel P, Mancini J (2016) Sexual health problems in French cancer survivors 2 years after diagnosis-the national VICAN survey. J Cancer Survivorship 10(3):600-609

5. Carter J, Lacchetti C, Andersen BL, Barton DL, Bolte S, Damast S, Diefenbach MA, DuHamel K, Florendo J, Ganz PA, Goldfarb $S$ (2018) Interventions to address sexual problems in people with cancer: American Society of Clinical Oncology clinical practice guideline adaptation of Cancer Care Ontario guideline. J Clin Oncol 36(5):492-511 
6. England NHS (2016) Implementing the cancer taskforce recommendations: commissioning person centred care for people affected by cancer. London: NHS England. Available at: https:// www.england.nhs.uk/wp-content/uploads/2016/04/cancer-guidv1.pdf. Accessed March 2020

7. Cancer Australia (2019) Psychosexual care of women. Australia: Cancer Australia. Available at: https://gynaecological-cancer. canceraustralia.gov.au/health-professionals/psychosexual-carewomen. Accessed March 2020

8. Charif AB, Bouhnik AD, Courbiere B, Rey D, Preau M, Bendiane MK et al (2016) Patient discussion about sexual health with health care providers after cancer-a national survey. J Sex Med 13(11):1686-1694. https://doi.org/10.1016/j.jsxm.2016.09.005

9. Sporn NJ, Smith KB, Pirl WF, Lennes IT, Hyland KA, Park ER (2015) Sexual health communication between cancer survivors and providers: how frequently does it occur and which providers are preferred? Psychooncology 24(9):1167-1173. https://doi.org/ 10.1002/pon.3736

10. Frederick NN, Campbell K, Kenney LB, Moss K, Speckhart A, Bober SL (2018) Barriers and facilitators to sexual and reproductive health communication between pediatric oncology clinicians and adolescent and young adult patients: the clinician perspective. Pediatr Blood Cancer 65(8):e27087. https://doi.org/10.1002/pbc. 27087

11. O’Connor SR, Connaghan J, Maguire R, Kotronoulas G, Flannagan C, Jain S, Brady N, McCaughan E (2019) Healthcare professional perceived barriers and facilitators to discussing sexual wellbeing with patients after diagnosis of chronic illness: a mixed-methods evidence synthesis. Patient Ed and Couns 102(5):850-863

12. McCaughan E, Flannagan C, Brady N, Parahoo K, Connaghan J, Maguire R, Steele M, Thompson S, Jain S, Kirby M and O'Connor SR (2021) Effects of a brief e-learning resource on sexual attitudes and beliefs of healthcare professionals working in prostate cancer care: a single arm pre and post-test study. (Submitted for peer review.)

13. Quinn GP, Bowman Curci M, Reich RR, Gwede CK, Meade CD, ENRICH/ECHO Working Group, Vadaparampil ST (2019) Impact of a web-based reproductive health training program: ENRICH (Educating Nurses about Reproductive Issues in Cancer Healthcare). Psycho-Onco. 28(5):1096-1101

14. Reese JB, Lepore SJ, Daly MB, Handorf E, Sorice KA, Porter LS, Tulsky JA, Beach MC (2019) A brief intervention to enhance breast cancer clinicians' communication about sexual health: feasibility, acceptability, and preliminary outcomes. Psycho-Onco 28(4):872-879

15. Wang LY, Pierdomenico A, Brandt R, Lefkowitz A (2015) Female sexual health training for oncology providers: new applications. Sex Med 3(3):189-197

16. McCaughan E, Parahoo K, Flannagan C, Maguire R, Connaghan J, Steele M, Thompson S, Jain S, Kirby M, Brady N, O'Connor SR (2020) Development of a conceptual framework to improve sexual wellbeing communication in routine prostate cancer care. Patient Educ Couns 103(6):1150-1160

17. French SD, Green SE, O'Connor DA, McKenzie JE, Francis JJ, Michie S, Buchbinder R, Schattner P, Spike N, Grimshaw JM (2012) Developing theory-informed behaviour change interventions to implement evidence into practice: a systematic approach using the Theoretical Domains Framework. Implement Sci $7(1): 1-8$

18. Ajzen I (1985) From intentions to actions: a theory of planned behavior. Action control. Springer, Berlin, Heidelberg, pp 11-39

19. Bandura A (1986) Social foundations of thought and action: a social cognitive theory. Prentice-Hall, Englewood Cliffs

20. Yardley L, Morrison L, Bradbury K, Muller I (2015) The personbased approach to intervention development: application to digital health-related behavior change interventions. J Med Internet Res 17(1):e30. https://doi.org/10.2196/jmir.4055

21. Engel GL (1977) The need for a new medical model: a challenge for biomedicine. Science 196(4286):129-136

22. Van den Haak MJ, De Jong MD, Schellens PJ (2007) Evaluation of an informational web site: three variants of the think-aloud method compared. Tech Commun 54(1):58-71

23 Stirman SW, Baumann AA, Miller CJ (2019) The FRAME: an expanded framework for reporting adaptations and modifications to evidence-based interventions. Implement Sci 14(1):58. https:// doi.org/10.1186/s13012-019-0898-y

24. Moore G, Campbell M, Copeland L, Craig P, Movsisyan A, Hoddinott P, Littlecott H, O'Cathain A, Pfadenhauer L, Rehfuess E, Segrott J (2021) Adapting interventions to new contexts-the ADAPT guidance. BMJ 374:n1679

25. Bradbury K, Steele M, Corbett T, Geraghty AW, Krusche A, Heber E, Easton S, Cheetham-Blake T, Slodkowska-Barabasz J, Müller AM, Smith K (2019) Developing a digital intervention for cancer survivors: an evidence-, theory-and person-based approach. NPJ Digit Med 2(1):1-3

26. Braun V, Clarke V (2006) Using thematic analysis in psychology. Qual Res Psychol 3(2):77-101. https://doi.org/10.1191/14780 88706qp063oa29

27. Muller I, Santer M, Morrison L, Morton K, Roberts A, Rice C, Williams M, Yardley L (2019) Combining qualitative research with PPI: reflections on using the person-based approach for developing behavioural interventions. Res Involv Engagem 5(1): $1-8$

28. Allen D, Cree L, Dawson P, El Naggar S, Gibbons B, Gibson J, Gill L, Gwernan-Jones R, Hobson-Merrett C, Jones B, Khan H (2020) Exploring patient and public involvement (PPI) and coproduction approaches in mental health research: learning from the PARTNERS2 research programme. Res Involv Engagem 6(1):1-11

29. Coulman KD, Nicholson A, Shaw A, Daykin A, Selman LE, Macefield R, Shorter GW, Cramer H, Sydes MR, Gamble C, Pick ME (2020) Understanding and optimising patient and public involvement in trial oversight: an ethnographic study of eight clinical trials. Trials 21(1): $1-5$

30. Morrison L, Muller I, Yardley L, Bradbury K (2018) The personbased approach to planning, optimising, evaluating and implementing behavioural health interventions. Eur Health Psychol 20(3):464-469

31. Ericsson KA, Simon HA (1998) How to study thinking in everyday life: contrasting think-aloud protocols with descriptions and explanations of thinking. Mind Cult Act 5(3):178-186

32. Lau R, Stevenson F, Ong BN, Dziedzic K, Treweek S, Eldridge S, Everitt H, Kennedy A, Qureshi N, Rogers A, Peacock R (2015) Achieving change in primary care-causes of the evidence to practice gap: systematic reviews of reviews. Implement Sci 11(1): $1-39$

33. Health Research Authority (2017) UK policy framework for health and social care research. Health Do, ed

34. Carolan C, Davies CL, Crookes P, McGhee S, Roxburgh M (2020) COVID 19: Disruptive impacts and transformative opportunities in undergraduate nurse education. Nurse Educ Pract 46:102807. https://doi.org/10.1016/j.nepr.2020.102807

35. Afiyanti Y, Keliat B, Ruwaida I, Rachmawati IN, Agustini N (2016) Improving quality of life on cancer patient by implementation of psychosexual health care. Jurnal Ners 11(1):7-16

36. Jonsdottir JI, Zoëga S, Saevarsdottir T, Sverrisdottir A, Thorsdottir T, Einarsson GV, Gunnarsdottir S, Fridriksdottir N (2016) Changes in attitudes, practices and barriers among oncology health care professionals regarding sexual health care: outcomes from a 2-year educational intervention at a University Hospital. Euro J Onco Nurs 21:24-30 
37. Sinclair PM, Levett-Jones T, Morris A, Carter B, Bennett PN, Kable A (2017) High engagement, high quality: a guiding framework for developing empirically informed asynchronous e-learning programs for health professional educators. Nurs Health Sci 19(1):126-137

38. Husmann M, Spiegel M, Murolo A, Norrie MC. (2016) UI testing cross-device applications. In Proceedings of the 2016 ACM International Conference on Interactive Surfaces and Spaces 179-188. https://doi.org/10.1145/2992154.2992177
39. Papadopoulou C, Sime C, Rooney K, Kotronoulas G (2019) Sexual health care provision in cancer nursing care: a systematic review on the state of evidence and deriving international competencies chart for cancer nurses. Int J Nurs Stud 100:103405. https://doi.org/10.1016/j.ijnurstu.2019.103405

Publisher's note Springer Nature remains neutral with regard to jurisdictional claims in published maps and institutional affiliations. 